\title{
Applying the 2005 Canadian Hypertension Education Program recommendations: 4. Managing uncomplicated hypertension
}

$\mathrm{H}$ ypertension is a major risk factor for cardiovascularrelated disease and death worldwide. Although it is one of the most common reasons for physician visits, hypertension is often undertreated. To facilitate the management of hypertension, the Canadian Hypertension Education Program provides recommendations that are updated yearly. Using a hypothetical case, we discuss the key 2005 recommendations for managing uncomplicated hypertension. Uncomplicated hypertension refers to hypertension without the presence of comorbid conditions such as diabetes mellitus, chronic kidney disease or cardiac disease, which would require a specific antihypertensive agent.

\section{Nadia A. Khan}

Division of General Internal Medicine

University of British Columbia

Vancouver, BC

Pavel Hamet

Faculté de medicine

Université de Montréal

Montréal, Qué.

Richard Z. Lewanczuk

Division of Endocrinology

University of Alberta

Edmonton, Alta.

For the Canadian Hypertension

Education Program

CASE: A 64-year-old woman presents in your office for follow-up with blood pressure that has been elevated over the past 2 months (at 3 previous office visits, her blood pressure was $178 / 96 \mathrm{~mm} \mathrm{Hg}$, $170 / 94 \mathrm{~mm} \mathrm{Hg}$ and 168/96 mm Hg), even though she is following the DASH diet and getting 30 minutes of aerobic exercise 5 days per week. Her medical history includes dyslipidemia and hypertension. She has no target organ damage and no other risk factors for cardiovascular disease. She works as an accountant and does not smoke or drink alcohol. Her only medication is pravastatin for her dyslipidemia. The results of her physical examination are otherwise unremarkable.

Question: Should I give this patient pharmacotherapy?

Comment: The decision to begin antihypertensive drug therapy must take into account the patient's future cardiovascular risk. "White coat" (or office-induced) hypertension may also need to be excluded before drug therapy is started. Given this patient's blood pressure and cardiovascular risk factors (age and dyslipidemia), she would benefit from an antihypertensive agent. The results of numerous clinical studies have demonstrated that with moderately elevated blood pressure $(\geq 160 \mathrm{~mm} \mathrm{Hg}$ systolic or $\geq 100 \mathrm{~mm} \mathrm{Hg}$ diastolic), antihypertensive therapy leads to $20 \%-25 \%$ reductions in cardio- vascular morbidity and 5\%-15\% reductions in mortality. ${ }^{1}$ When blood pressure is mildly increased (140-159 mm Hg systolic or 90-99 $\mathrm{mm} \mathrm{Hg}$ diastolic), patients with macrovascular target organ damage or a number of cardiovascular risk factors would have sufficiently increased risk to warrant initiating drug therapy.

Question: Which antihypertensive agents should I initiate?

Comment: Variables involved in the choice of agent include the patient's age, preferences, comorbid conditions, and drug allergy or sensitivity profile; whether the patient is pregnant or lactating; and the cost of the drugs (Box 1). For this patient,
Box 1: Potential reasons why adults with uncomplicated hypertension may not respond to antihypertensive drug therapy

"White coat" (office-induced) hypertension

Noncompliance

- Dietary

- Medication

Other conditions

- Obesity

- Cigarette smoking

- Excessive alcohol consumption

- Sleep apnea

- Chronic pain

Drug interactions

- NSAIDS (including cyclooxygenase-2 inhibitors)

- Oral contraceptives

- Corticosteroids and anabolic steroids

- Sympathomimetics and decongestants

- Cocaine

- Amphetamines

- Erythropoietin

- Cyclosporine, tacrolimus

- Licorice

- Certain dietary supplements (e.g., ephedra, ma haung)

Suboptimal treatment regimens

- Underdosing of medications

- Inappropriate combinations of antihypertensive agents

Volume overload

- Excessive salt intake

- Renal sodium retention (pseudotolerance)

Secondary cause of hypertension

- Chronic kidney disease

- Renovascular disease

- Primary hyperaldosteronism

- Thyroid disease

- Pheochromocytoma and other rare endocrine disorders 
any single agent from the following drug classes would be an appropriate first-line option: low-dose thiazide diuretics, angiotensin-converting enzyme (ACE) inhibitors, long-acting calcium-channel blockers or angiotensin-receptor blockers (Table 1). A meta-analysis of 192478 patients highlighted the importance of blood pressure lowering and found no difference in cardiovascular morbidity or total mortality between any of these drug classes compared with low-dose diuretics.

Table 1: Contraindications and relative contraindications associated with each major class of antihypertensive agents*

\begin{tabular}{ll}
\hline Major drug class & \multicolumn{1}{c}{$\begin{array}{c}\text { Contraindications and } \\
\text { relative contraindications }\end{array}$} \\
\hline $\begin{array}{l}\text { Low-dose thiazide } \\
\text { diuretic }\end{array}$ & $\begin{array}{l}\text { Anuric renal failure } \\
\text { Pregnancy }\end{array}$ \\
\hline
\end{tabular}

Angiotensinconverting enzyme (ACE) inhibitor

Angioedema (hereditary, idiopathic or related to previous ACE inhibitor use) Bilateral renal artery stenosis Hyperkalemia

Caution in patients with severe aortic stenosis

Pregnancy

\begin{tabular}{ll}
$\begin{array}{l}\text { Angiotensin- } \\
\text { receptor blocking } \\
\text { agent }\end{array}$ & $\begin{array}{l}\text { Bilateral renal artery stenosis } \\
\text { Caution in patients with severe aortic } \\
\text { stenosis } \\
\text { Pregnancy }\end{array}$ \\
$\begin{array}{l}\text { Nondihydropyridine } \\
\text { calcium-channel } \\
\text { blocker }\end{array}$ & $\begin{array}{l}\text { Severe left ventricular dysfunction } \\
\text { Sick sinus syndrome } \\
\text { Second- or third-degree heart block } \\
\text { Resting bradycardia } \\
\text { Pregnancy }\end{array}$ \\
\hline $\begin{array}{l}\text { Dihydropyridine } \\
\text { calcium-channel } \\
\text { blocker }\end{array}$ & $\begin{array}{l}\text { Caution in patients with severe aortic } \\
\text { stenosis } \\
\text { Long-acting nifedipine can be used in } \\
\text { pregnancy }\end{array}$ \\
\hline -Blocker & $\begin{array}{l}\text { Asthma } \\
\text { Severe peripheral vascular disease } \\
\text { Sick sinus syndrome } \\
\text { Resting bradycardia } \\
\text { Second- or third-degree heart block } \\
\text { Hypoglycemia-prone diabetic patients } \\
\text { Labetolol can be used in pregnancy }\end{array}$ \\
& $\begin{array}{l}\text { Caution in those with severe coronary } \\
\text { artery disease or recent acute } \\
\text { myocardial infarction } \\
\text { Cerebrovascular disease or other CNS } \\
\text { disorder that may predispose to CNS } \\
\text { depression } \\
\text { Chronic kidney disease } \\
\text { Methyldopa can be used in pregnancy }\end{array}$ \\
\hline$\alpha-1$ Blocker, \\
centrally acting \\
agent
\end{tabular}

Note: $\mathrm{CNS}=$ central nervous system

*Allergy to the drug or component of the formulation is a contraindication to the use of the drug.
Although $\beta$-blockers are a reasonable option for first-line therapy in younger patients and those with existing cardiovascular disease, they are not recommended as first-line monotherapy in patients 60 years of age or more. In a meta-analysis of patients 60 years and older, $\beta$ blocker monotherapy was no more effective than placebo in reducing the risk of coronary artery disease, cardiovascularrelated death or death due to any cause. ${ }^{2}$ In the ALLHAT study, $\alpha$-blockers were associated with a higher incidence of heart failure than were thiazide diuretics. ${ }^{3}$ Thus, $\alpha$-blockers are not considered first-line agents for managing hypertension.

Question: I've decided to start this patient with hydrochlorothiazide at $12.5 \mathrm{mg}$ per day. How should I monitor her for adverse effects?

Comment: Metabolic disturbances such as hypokalemia, dyslipidemia and hyperglycemia occur infrequently with low doses of thiazide diuretic. Despite the occurrence of these abnormalities, the overall cardiovascular benefits remain. Evidence is lacking on the optimal frequency and timing of monitoring for adverse effects associated with antihypertensive agents. In our opinion, all patients starting on thiazide diuretics (even at low doses) should be screened after 4-6 weeks for glucose, electrolyte, creatinine and serum total cholesterol levels in case metabolic disturbances occur. Any abnormalities should prompt closer follow-up and correction. The risk of hypokalemia can be minimized among patients receiving thiazide diuretic monotherapy through the use of potassium-sparing agents (e.g., triamterene, aldactone, amiloride). For those taking ACE inhibitors or angiotensin-receptor blockers, serum creatinine levels should be monitored 2-4 weeks after therapy starts. Serum potassium and creatinine levels should be monitored at least 1-2 times per year there- after. In general, if there are adverse effects with a single agent, another drug from any of the other appropriate first-line agents should be substituted.

Patients given drug therapy should return for follow-up blood pressure monitoring every 1-2 months until their target level is reached. Patients with severe hypertension, intolerance to antihypertensive drugs or target organ damage may need to be monitored more frequently. Once the target level is reached, blood pressure should be monitored at intervals of 3-6 months.

Question: After increasing hydrochlorothiazide to a standard dose (25 $\mathrm{mg}$ per day), the patient's blood pressure is $162 / 92 \mathrm{~mm} \mathrm{Hg}$. Since this level is still above the target $(<140 / 90 \mathrm{~mm} \mathrm{Hg})$, what medication should be added?

Comment: For most patients, reaching a target of less than 140/90 $\mathrm{mm} \mathrm{Hg}$ requires 2 or more antihypertensive agents at standard doses. In a metaanalysis of 50 placebo-controlled trials evaluating drugs from 2 different classes separately and in combination, reductions in blood pressure with combination drug therapy were additive, and adverse effects were reported less often than expected. ${ }^{4}$ Thus, if the blood pressure target has not been reached at the standard dose (rather than the maximum dose) of an antihypertensive agent, a second antihypertensive agent should be started and the dosage increased to the standard amount until the blood pressure target is met. Currently, there is little prospective evidence supporting starting with a combination of 2 drugs, although trials are ongoing.

For this patient, and in general, thiazide diuretics can be combined with any of the other major drug classes (calciumchannel blockers, $\beta$-blockers, ACE inhibitors or angiotensinreceptor blockers). On the basis of their complementary physiologic effects, other useful combinations include a calciumchannel blocker with either an 
ACE inhibitor or angiotensinreceptor blocker. If blood pressure is still not controlled with 2 agents or if there are adverse effects, another agent should be added from the remaining first-line agents. Other classes of antihypertensive drugs, such as $\alpha$-blockers and centrally acting agents, may be used if additional therapy is needed for blood pressure control.

Question: Two months later, the patient is taking 3 agents at standard dosages: hydrochlorothiazide $25 \mathrm{mg}$ per day, enalapril $10 \mathrm{mg}$ twice daily and amlodipine $10 \mathrm{mg}$ per day. However, her blood pressure remains above target at 152/90 $\mathrm{mm} \mathrm{Hg}$. What should I consider now?

Comment: The average reduction in blood pressure with a single agent at standard dose is 9.1 (8.8-9.3) mm Hg systolic and 5.5 (5.4-5.7) $\mathrm{mm} \mathrm{Hg} \mathrm{dia-}$ stolic. ${ }^{4}$ Using 3 agents, one would expect an even greater reduction in blood pressure, which is not apparent in our patient. When the patient is not responding to therapy and suboptimal treatment has been excluded, one must consider nonadherence, possible medication adverse effects, or resistant hypertension (Box 1).

Alternatively, if the patient describes symptoms of hypotension or reports lower blood pressure readings outside of the office setting, consider officeinduced hypertension. A 24hour ambulatory blood pressure measuring device can be used to confirm this diagnosis. If the target blood pressure remains difficult to achieve, referral to a hypertension specialist should be considered.

On further discussion with this patient, she had stopped taking the enalapril because of a dry cough. We recommended that the enalapril be replaced with atenolol $50 \mathrm{mg}$ daily. At the next follow-up visit, her blood pressure was $138 / 85 \mathrm{~mm} \mathrm{Hg}$, the target level.
Box 2: Factors associated with nonadherence and strategies to improve nonadherence

Factors associated with nonadherence

- Adverse reactions to antihypertensive agent

- Cost of antihypertensive agent

- Complicated dosing regimen

- Number of pills taken

Strategies to improve nonadherence

- Simplify medication regimens to once-daily dosing

- Use electronic medication compliance aids

- Tailor pill-taking to the patients' daily habits

- Encourage patient participation in monitoring blood pressure

- Educate patients and patients' families about hypertension and the treatment regimen

Question: Many patients complain about "having to take so many pills." What strategies can help to improve adherence to the therapeutic regimen?

Comment: Nonadherence to the therapeutic regimen may occur for a variety of reasons. Several strategies that can help to improve adherence are shown in Box 2.

\section{This article has been peer reviewed.}

Competing interests: None declared for $\mathrm{Na}-$ dia Khan. Pavel Hamet has received consultant and speaker fees and travel assistance from Laboratoires Servier, Pfizer Canada and Bristol Myers Squibb. Richard Lewanczuk has received speaker fees from Bristol Myers Squibb, Biovail, GlaxoSmithKline, Merck-

Frosst, Novartis and Pfizer.

\section{References}

1. Psaty BP, Lumley T, Furberg CD, Schellenbaum G, Pahor M, Alderman $\mathrm{MH}$, et al. Health outcomes associated with various antihypertensive therapies used as first-line agents a network meta-analysis. $7 A M A$ 2003; 289:2534-44.

2. Messerli FH, Grossman E, Goldbourt U. Are beta-blockers efficacious as first-line therapy for hypertension in the elderly? A systematic review. 7AMA 1998;279(23):1903-7.

3. ALLHAT Collaborative Research Group. Major cardiovascular events in hypertensive patients randomized to doxazosin vs chlorthalidone: the antihypertensive and lipid-lowering treatment to prevent heart attack trial (ALLHAT). FAMA 2000;283(15): 1967-75.

4. Law MR, Wald NJ, Morris JK, Jordan RE. Value of low dose combination treatment with blood pressure lowering drugs: analysis of 354 randomised trials. BM7 2003;326:1427-30.

Articles to date in this series

McAlister FA, Wooltorton E, Campbell NRC. The Canadian Hypertension Education Program (CHEP) recommendations: launching a new series. CMAJ 2005;173(5):508-9.

Bolli P, Myers M, McKay D. Applying the 2005 Canadian Hypertension Education Program recommendations: 1. Diagnosis of hypertension. CMAJ 2005;173(5):480-3.

Hemmelgarn BR, Grover S, Feldman RD. Applying the 2005 Canadian Hypertension Education Program recommendations: 2. Assessing and reducing global atherosclerotic risk among hypertensive patients [published erratum appears in CMAJ 2005;173(7):738]. CMAJ 2005;173(6):593-5.

Padwal R, Campbell N, Touyz RM. Applying the 2005 Canadian Hypertension Education Program recommendations: 3. Lifestyle modifications to prevent and treat hypertension. CMAJ 2005;173(7):749-51. 